\title{
Significance of Interdialytic Weight \\ Gain versus Chronic Volume Overload: Consensus Opinion
}

\author{
Manfred Hecking ${ }^{a} \quad$ Angelo Karaboyas $^{b} \quad$ Marlies Antlanger ${ }^{a} \quad$ Rajiv Saran $^{c}$ \\ Volker Wizemann ${ }^{f}$ Charles Chazot ${ }^{\text {h }}$ Hugh Rayner $^{i}$ Walter H. Hörl ${ }^{\text {a }}$ \\ Ronald L. Pisoni $^{\text {b }}$ Bruce M. Robinson ${ }^{b}$ Gere Sunder-Plassmann ${ }^{a}$ \\ Ulrich Moissl $^{g}$ Peter Kotanko $^{d}$ Nathan W. Levin ${ }^{d}$ Marcus D. Säemann ${ }^{a}$ \\ Kamyar Kalantar-Zadeh ${ }^{\mathrm{e}}$ Friedrich K. Port ${ }^{\mathrm{b}}$ Peter Wabel ${ }^{\mathrm{g}}$ \\ ${ }^{a}$ Department of Nephrology, Medical University of Vienna, Vienna, Austria; ${ }^{\mathrm{b}}$ Arbor Research Collaborative \\ for Health, and 'University of Michigan (UM), Department of Nephrology and UM-Kidney Epidemiology and \\ Cost Center, Ann Arbor, Mich., ${ }^{\mathrm{d}}$ Renal Research Institute, New York, N.Y., and ${ }^{\mathrm{e} H a r o l d ~ S i m m o n s ~ C e n t e r ~ f o r ~}$ \\ Kidney Research and Epidemiology, Torrance, Calif., USA; ${ }^{f}$ Georg-Haas Dialysezentrum Giessen, Giessen, and

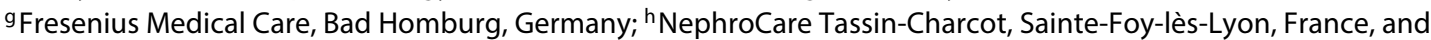 \\ 'Heart of England NHS Foundation Trust, Birmingham, UK
}

\section{Key Words}

Hemodialysis · Fluid/electrolytes · Epidemiology · Volume overload · Interdialytic weight gain · Outcomes, additional

\begin{abstract}
Predialysis volume overload is the sum of interdialytic weight gain (IDWG) and residual postdialysis volume overload. It results mostly from failure to achieve an adequate volume status at the end of the dialysis session. Recent developments in bioimpedance spectroscopy and possibly relative plasma volume monitoring permit noninvasive volume status assessment in hemodialysis patients. A large proportion of patients have previously been shown to be chronically volume overloaded predialysis (defined as $>15 \%$ above 'normal' extracellular fluid volume, equivalent to $>2.5$ liters on average), and to exhibit a more than twofold increased mortality risk.
\end{abstract}

By contrast, the magnitude of the mortality risk associated with IDWG is much smaller and only evident with very large weight gains. Here we review the available evidence on volume overload and IDWG, and question the use of IDWG as an indicator of 'nonadherence' by describing its association with postdialysis volume depletion. We also demonstrate the relationship between IDWG, volume overload and predialysis serum sodium concentration, and comment on salt intake. Discriminating between volume overload and IDWG will likely lead to a more appropriate management of fluid withdrawal during dialysis. Consensually, the present authors agree that this discrimination should be among the primary goals for dialysis caretakers today. In consequence, we recommend objective measures of volume status beyond mere evaluations of IDWG.

Copyright $\odot 2013$ S. Karger AG, Basel

\section{KARGER}

E-Mail karger@karger.com www.karger.com/ajn
(C) 2013 S. Karger AG, Basel

0250-8095/13/0381-0078\$38.00/0
Friedrich K. Port, MD, MS

Arbor Research Collaborative for Health

340 East Huron Street, Suite 300

Ann Arbor, MI 48104 (USA)

E-Mail Friedrich.port@ arborresearch.org 
The volume status of a patient on intermittent hemodialysis (HD) therapy varies across the week. Body volume rises between dialysis sessions and falls during treatments, like waves on the ocean. These waves are only part of the total volume status - underlying the waves is the postdialysis volume status, which ranges from volume depletion to volume overload and can be compared to the level of the tide (fig. 1). The tide elevation is defined primarily by the nephrologist's setting of the postdialysis weight. The surface waves - interdialytic weight gain (IDWG), corresponding to ultrafiltration losses during dialysis - are mostly influenced by oral fluid intake minus residual urine output (when present) and insensible fluid losses. Oral fluid intake is driven largely by thirst due to sodium intake from food [1] and to a lesser degree from dialysate sodium (DNa) concentration or intradialytic, intravenous administration of saline. Other contributors to thirst may include high blood glucose levels in diabetic patients [2], potassium depletion, angiotensin II and psychological factors [3].

Advances in segmental and whole-body bioimpedance spectroscopy as well as relative plasma volume (RPV) monitoring have enabled a more reliable assessment of volume status [4-6]. Recent results obtained with whole-body bioimpedance spectroscopy indicate that an adequate postdialysis weight is not achieved in the majority of HD patients, leaving many patients chronically volume overloaded at all times, even postdialysis $[7,8]$. By contrast, those who reach a normal volume status or slight volume depletion by the end of dialysis are volume overloaded only temporarily.

The present article explores in detail the concepts of extracellular volume expansion and dry weight assessment, and reviews recent studies of volume overload and IDWG. Based on bioimpedance spectroscopy data from more than 3,000 patients, we also consider the association between volume overload and IDWG, and relate volume overload as well as IDWG with the individual predialysis serum sodium $(\mathrm{SNa})$ concentration. Our aim is to discriminate between recognition of volume status and IDWG as a way of improving management and outcomes for patients on dialysis.

A technical note: The terms fluid overload, volume overload and overhydration are often used interchangeably. Since 'hydration' refers strictly to water, while 'volume expansion' refers to the accumulation of isotonic fluid (salt and water), we primarily use the term volume overload or volume status. Similarly, the term extracellular water used in previous publications [9-12] has here been replaced by extracellular volume (ECV). Values for

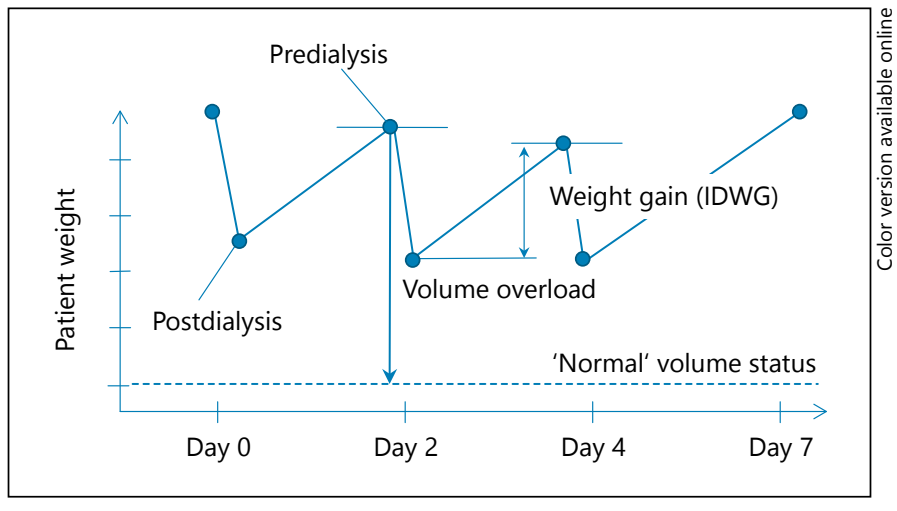

Fig. 1. Volume overload versus IDWG. The oscillation of the patient's volume status (= wave) is driven by weight gain (IDWG) and the ultrafiltration during intermittent HD. It is different from chronic volume overload (tide elevation). The patient weight at normal postdialysis volume status can be compared to the normal height null. Note: (1) The patient weight does not increase linearly, as might be assumed from the approximation made by this drawing. (2) When using the analogy of the ocean made in the text, it should be clarified that the absolute volume of the ocean does not change whatever the size of the waves is. (3) The patient weight, even at normal postdialysis volume status, may change over time based on high or low nutritional intake, albeit at much lower frequency than IDWG. (4) Volume depletion postdialysis is also important, as discussed in the text, but has not been included in this figure. (5) A cut-off for volume overload (>15\% of the presumably normal ECV of the patient, predialysis) was previously introduced to analyze the mortality risk $[9,12]$, based on previous work [7], and as discussed in the text. For a typical HD patient, 15\% ECV correspond roughly to 2.5 liters. At excessive weight gain above this level, complete fluid removal may not be reached during dialysis, so that normal postdialysis volume status may not be achieved.

ECV are reported in liters, when obtained by whole-body bioimpedance spectroscopy using the body composition monitor (BCM). The severity of volume overload (the volume excess) is described in liters and percent above 'normal' ECV. Volume status can also be assessed by various other technical devices, as discussed below.

\section{Extracellular Volume Expansion and the Dry Weight Concept}

In 1960, Scribner et al. [13] emphasized the importance of extracellular volume expansion in their preliminary report on the treatment of chronic uremia by intermittent dialysis: 'The combination of dietary sodium restriction and ultrafiltration during dialysis permits regulation of extracellular volume. In time, it may be pos- 
sible to clarify the importance of the size of the extracellular space in the etiology of hypertension and the effect its size may have on modifying the response to anti-hypertensive therapy'.

Thus, two of the most relevant consequences of volume overload, hypertension and congestive heart failure, were clear to nephrologists early on. Very important pathophysiologic knowledge from the same time period was generated by Guyton [14, 15]. Improved diagnostic means have expanded the previous knowledge with regard to the consequences of volume overload (overviewed by Braam et al. [16]). For example, our understanding of heart disease in dialysis patients today includes left ventricular hypertrophy and diagnoses such as diastolic dysfunction, as well as heart failure with impaired or normal ejection fraction [17].

At the initiation of chronic dialysis therapy, many patients have clinically been described as hypertensive and volume-expanded [18]. Prior to the most recent developments in bioimpedance technology, the magnitude of volume overload was unclear in HD patients, and 'probing for dry weight' is still widely practiced to determine the appropriate postdialysis weight. Dry weight as a term has been variably interpreted [19], most probably because its clinical assessment is challenging. Agarwal and Weir [20] have given an interesting overview on how the dry weight concept changed over time, as a consequence of augmented clinical knowledge and availability of technical tools.

Among the most experienced clinicians, Charra et al. [21] have defined dry weight as 'the postdialysis body weight that allows normal blood pressure before and at the end of the HD session without antihypertensive medications, without clinical sign of over- or underhydration and despite the IDWG'. Using their 'probing for dry weight' concept in combination with dietary salt restriction in a stringent way permits as many as $90 \%$ of $\mathrm{HD}$ patients to be maintained without antihypertensive medication [22]. Excellent survival results are also associated with this practice, not only in patients on 'long, slow dialysis' [23], but also when strict volume control is applied with conventional dialysis times [24].

Recent international data, however, show that a large majority of HD patients take antihypertensive medication [25]. According to the previous dry weight definition by Charra et al. [21], this practice may be an indication that dry weight is not reached in the majority of the $\mathrm{HD}$ patients. Of note, in a recent study on stable HD patients, Chazot et al. [9] found that blood pressure did not differ between those with and without volume over- load, while other studies showed variable degrees of association between volume overload and hypertension $[7,26]$. An increased efficiency of today's antihypertensive agents and rising prevalence of myocardial failure in the HD population might have contributed to these somewhat discrepant findings. Possibly modifying the earlier concept of an almost obligatory connection between hypertension and volume overload at the initiation of dialysis, normal blood pressure (and even lower than normal blood pressure) may not rule out volume overload today. Nevertheless, even nowadays in incident HD patients, the classical approach of 'probing for dry weight' is efficient in decreasing blood pressure and allows withdrawal of antihypertensives, while the concomitant blood pressure decline is associated with better survival [27]. A beneficial decline in blood pressure is not to be confused with intradialytic hypotension, one of the possible consequences of overzealous probing for dry weight.

\section{Interdialytic Weight Gain: Reported Causes and Consequences}

IDWG is defined as the difference between a patient's predialysis weight and the weight at the end of the prior HD session (fig. 1). Numerous reports have dealt with IDWG, and have focused on the following areas:

(1)IDWG as a measure of nonadherence: For decades it has been emphasized that adherence to fluid restriction is necessary to reduce IDWG, and IDWG has been equated with nonadherence [28-38] (in an oversimplified disregard of the thirst mechanism, as specified below).

(2)Psychological aspects of IDWG: Since IDWG has been regarded as related to nonadherence, much attention has been paid to psychological aspects of IDWG and ways to help patients modify their behavior $[31,34,35$, 39-49, reviewed in 50].

(3)IDWG as a marker of better nutrition: Several studies have found that IDWG was associated with better nutritional status [51-57], suggesting a role of greater appetite and higher food and fluid intake.

(4)IDWG and sodium intake: Dietary salt restriction [22, $24,58-61]$ can effectively reduce the IDWG, and lowering of the DNa concentration also has an effect [6267], since dialysate-to-SNa concentration gradients are associated with IDWG [68-71]. The amount of IDWG associated with the isolated $\mathrm{DNa}$ prescription is small however, because the $\mathrm{SNa}$ component of the
Hecking et al. 
dialysate-to-SNa concentration gradient also contributes to IDWG (discussed below).

(5)IDWG and glycemic control in diabetic patients: Poor glycemic control with hyperglycemia is linked to higher IDWG [72].

Many of the aspects mentioned above are expressed in the title of an editorial by Tomson [73]: 'Advising dialysis patients to restrict fluid intake without restricting sodium intake is not based on evidence and a waste of time'. Specifically, Tomson argued that salt reduction would lead to the most efficient reduction of IDWG, while 'asking patients with severe thirst to drink less than 1 liter a day is illogical and inhumane'. Tomson's strong statement is supported by evidence: From food questionnaires in 91 dialysis patients, Chazot et al. [1] identified a strong, significant, positive association between salt intake and fluid intake $(\mathrm{R}=0.47, \mathrm{p}<0.0001)$, independent of protein and caloric intake (stepwise regression approach).

A subjective feeling of a dry mouth (xerostomia) could also be a potentially important stimulus for fluid intake. Bots et al. [3] analyzed and identified significant associations between scores on the Xerostomia Inventory, the Dialysis Thirst Inventory and IDWG. However, this approach was criticized by Dorhout Mees [74], who argued that the relationship between IDWG and feeling of thirst would 'almost certainly be due to more salt consumption, the natural thirst stimulus, while the relationship between dry mouth and thirst hardly needed statistical proof.

\section{Interdialytic Weight Gain and Mortality}

Several studies have analyzed the association between IDWG and mortality:

(1)In a random sample of US HD patients, IDWG $>4.8 \%$ of body weight was associated with mortality after adjustment (hazard ratio (HR) 1.12, 95\% confidence interval (CI) 1.02-1.23) [75].

(2)In the Dialysis Outcomes and Practice Patterns Study (DOPPS), the relative mortality risk (after adjustment) was increased for IDWG $>5.7 \%$ of body weight (i.e. $>4 \mathrm{~kg}$ in a $70-\mathrm{kg}$ patient, HR $1.12,95 \%$ CI $1.00-1.26)$ [38].

(3)In a large US registry analysis, mortality risk was increased after adjustment for case mix, with HR 1.25 for IDWG $\geq 4.0 \mathrm{~kg}$ (95\% CI 1.12-1.39) [76].

In all three studies $[38,75,76]$, only the extremes of IDWG ( $>4.8 \%$ of body weight, $>5.7 \%$ of body weight, and $\geq 4.0 \mathrm{~kg}$, respectively) were associated with adverse outcomes, and the mortality risk was also relatively small (HR 1.12-1.25). Results on the association between
IDWG and mortality were moreover not adjusted for ultrafiltration rates. As higher ultrafiltration rates have been shown to be associated with a higher mortality risk [77, 78], IDWG might have been associated even less strongly with mortality risk if adjustments for ultrafiltration rates had been performed.

\section{Interdialytic Weight Gain, Predialysis Serum Sodium \\ Concentration, Dialysate Sodium Prescription and \\ Outcomes}

Because IDWG is associated with mortality, and the dialysate-to-SNa concentration gradient is associated with IDWG $[65,69,70]$, Hecking et al. [79] analyzed the mortality risks associated with predialysis $\mathrm{SNa}$ and with $\mathrm{DNa}$ prescriptions. A higher predialysis $\mathrm{SNa}$ level was associated with lower adjusted all-cause mortality in a continuous model (HR 0.95 per $1 \mathrm{mEq} / 1,95 \%$ CI $0.93-0.97$ ), consistent with results from the HEMO study [80]. DNa prescription was not associated with mortality overall, and statistical adjustments for IDWG did not modify the HR for mortality [79]. This study separated the role of $\mathrm{SNa}$ and $\mathrm{DNa}$, and its findings explained that the relationship between dialysate-to-SNa concentration gradients and mortality was driven by a low $\mathrm{SNa}$.

In a subsequent larger DOPPS analysis, higher $\mathrm{DNa}$ was associated with a higher IDWG at all levels of predialysis $\mathrm{SNa}$ [81] confirming previous observational [65, 69, $70]$ and interventional studies [67, 82]. However, the magnitude of increased IDWG was small $(0.17 \%$ of postdialysis weight per $2 \mathrm{mEq} / \mathrm{l}$ higher $\mathrm{DNa}$ in a continuous model). IDWG was significantly smaller in patients with higher predialysis $\mathrm{SNa}$ [79]. Therefore, a complete interpretation of IDWG and dialysate-to-SNa concentration gradient $[65,69,70]$ should take into account both the $\mathrm{DNa}$ and $\mathrm{SNa}$ components of the sodium gradient, because either one of these components contributes to IDWG.

Finally, studying outcomes associated with 'baseline' $\mathrm{DNa}$ at the patients' entry into the DOPPS, hospitalization rates were significantly lower with higher $\mathrm{DNa}$ (adjusted HR 0.97 per $2 \mathrm{mEq} / \mathrm{l}$ higher $\mathrm{DNa}$ in a continuous model, 95\% CI $0.95-1.00, \mathrm{p}=0.04$ ) and the mortality risk was clearly not increased. Our interpretation is conservative however because this analysis [81] and also a subsequent sensitivity analysis that excluded Japanese facilities (where patients typically have the best survival rates, but are prescribed the highest $\mathrm{DNa}$ ) showed a lower mortality risk for patients receiving higher $\mathrm{DNa}$ in 'nonindividualized $\mathrm{DNa}$ ' facilities (HR 0.91 per $2 \mathrm{mEq} / \mathrm{l}$ higher $\mathrm{DNa}, 95 \%$ CI 0.85-0.97) [83]. The distinction be- 
tween 'nonindividualized $\mathrm{DNa}$ ' facilities (defined as $90 \%$ of patients receiving a uniform $\mathrm{DNa}$ ) and individualized DNa' facilities (the remaining facilities) is important, because the associations identified in our study indicated that higher $\mathrm{DNa}$ in 'individualized $\mathrm{DNa}$ ' $\mathrm{fa}$ cilities was usually prescribed for sicker patients [81]. The mortality risk was therefore higher with higher $\mathrm{DNa}$ in 'individualized $\mathrm{DNa}$ ' facilities [81,83], but presumably as a consequence of the identified bias by indication.

Again, none of the reported associations regarding hospitalizations and mortality were altered by adjustment for IDWG, indicating that the higher IDWG due to higher $\mathrm{DNa}$ did not have a significant influence on the outcomes. Together, these reports confirm that only excessive IDWG may be a risk factor for mortality.

\section{Methods of Dry Weight Assessment: An Overview}

The analysis of the volume status of HD patients has been hampered by a lack of validated tools [18, 19, 84]. Whilst ultrasound of the inferior vena cava has been considered reliable in estimating changes of volume status [85], its detection limits are not sufficient [86], and the timing of its use increases its impracticality. The information derived from biochemical parameters, such as atrial natriuretic peptide, brain natriuretic peptide and cyclic guanosine monophosphate, is linked to volume status [87-91]. Using these parameters to set a patient's dry weight has remained a major challenge however, since they allow merely a crude detection of volume overload, and the role of these markers in helping to assess vascular volume remains yet to be shown.

\section{Bioimpedance Technology}

Bioimpedance devices pass a low-strength alternating current into the body [92], and bioimpedance, then, refers to the electrical properties of a biological tissue which can be measured when the current flows. The impedance varies with frequency and different tissue types, and varies sensitively with the underlying histology [93]. Resistance and capacitance of tissue are the two basic properties in bioimpedance, resistance being a measure of the extent to which an element opposes the flow of electrons, and capacitance an expression of the extent to which it stores and releases energy as the current and voltage fluctuate with each alternating current cycle [93]. Alternate currents with low frequency $(\leq 5 \mathrm{kHz})$ travel preferentially in the ECV (because the current cannot pass the cell membrane at low frequencies), whereas alternate currents with high frequency traverse both ECV and intracellular volume (ICV) compartments [94].

Monofrequency Bioimpedance. This approach is based on empirical models to separate between ECV and ICV assumptions which hold only true for subjects whose volume status is normal. Thus the clinical application of monofrequency bioimpedance analysis is questionable in patients on dialysis.

Multifrequency Bioimpedance. Among multifrequency bioimpedance methods, the most important distinction is between segmental versus whole-body bioimpedance spectroscopy.

(1)Segmental biompedance spectroscopy methods measure in various segments of the body, including arms, trunk, and leg or calf [95]. Among the two methods that measure at the calf, the more precise and better known method continuously monitors the change of resistance during volume reduction. By observing the flattening of the resistance curve during $\mathrm{HD}$, this method provides the means 'to reach the physiologic dry weight (here: lowest tolerated weight in HD patients)' [4]. Continuous calf bioimpedance spectroscopy has recently been validated [95-97], and reviewed [94], along with other methods of dry weight assessment. If commercially available, it could simplify the clinical probing for dry weight method. The continuous method cannot be used in peritoneal dialysis (PD) and chronic kidney disease (CKD) stage 3-4 patients, as $\mathrm{PD}$ and $\mathrm{CKD}$ stage 3-4 therapy does not offer phases of very rapid fluid reduction. In PD and CKD stage 3-4 patients, the resistance at the calf can be measured and then compared to reference values of healthy subjects by correcting for anthropometric parameters.

(2)Whole-body bioimpedance spectroscopy (e.g. Hydra Xitron, SFB 7 Impedimed, BCM Fresenius) separates between ECV and ICV by applying a frequency sweep from 3 to $1,000 \mathrm{kHz}$ through the entire patient. When volume overload is determined by BCM, it is calculated in liters, using a three-compartment physiologic tissue model based on fundamental physiologic tissue hydration constants [98]. Adjustments for gender or race need not be applied [99], and validation has been reported against gold standard methods of volume assessment and intradialytic weight loss [6].

A recent paper examined the different methods of assessing and predicting dry weight with bioimpedance [4]. These included the use of the continuous, segmental bioimpedance method (1), described above, and the
Hecking et al. 
Table 1. Practical distinctions between methods of volume status assessment

\begin{tabular}{|c|c|c|c|c|c|c|}
\hline Sensitivity to volume status & $+/-$ & + & + & + & + & + \\
\hline Accuracy of ECV & - & - & $+/-$ & + & - & - \\
\hline Ease of application & + & + & + & + & + & + \\
\hline Applicability to PD and CKD & + & + & - & + & - & + \\
\hline
\end{tabular}

Distinctions were made based on the literature reviewed and mentioned here. $+=$ Good; $-=$ bad; $+/-=$ mediocre.

whole-body method by BCM (2). The same patients were measured with both techniques during an intervention phase. The whole-body method predicted the target weight close to the physiologic boundaries of normal volume status. This prediction varied according to the degree of volume overload. The segmental method provided a means of probing for a tolerated weight by observing the flattening of the resistance curve. A combination of both techniques may well be useful, despite the challenge to implement two different methods into routine clinical practice.

Based on the literature reviewed and mentioned here, important practical distinctions between segmental and whole-body bioimpedance methods are schematically depicted in table 1 . In the same table, these methods are also compared with mono- and multifrequency bioimpedance in general, as well as RPV monitoring and detection of lung water using chest ultrasound (described below).

\section{Relative Plasma Volume Monitoring}

RPV monitoring technology uses optical transmission/optical absorbance [100] to measure the intradialytic concentration change of hemoglobin/hematocrit [101-103] or it uses ultrasound speed in blood to measure the concentration of total plasma proteins including hemoglobin [104-106]. The original aim of RPV monitors was to prevent intradialytic hypotension and related morbid events [107]. Various studies however have shown diverging results [108-111], even higher mortality and hospitalizations with the use of this technique [111].

Lopot et al. [112] described as early as 1996 that RPV monitoring can be used to determine a volume-overload- ed state in HD patients by separating patients with steep intradialytic RPV slopes from patients with flat slopes, flat intradialytic RPV slopes being associated with volume overload. Sinha et al. [113] recently demonstrated the following in participants from the 'Dry Weight Reduction in Hypertensive Hemodialysis Patients' (DRIP) trial, who also underwent successful intradialytic RPV monitoring, once during the 2-week period at baseline and in the last week of the 8-week trial:

(1)Probing dry weight led to steeper RPV slopes from baseline to the last week.

(2)Patients with flatter slopes at baseline had greater weight loss (suggesting that they were volume overloaded and had more weight to be taken off).

(3)Those with flatter RPV slopes at baseline also had the greatest reduction in interdialytic ambulatory systolic blood pressure upon probing dry weight [5].

(4)Vice versa, patients with steeper slopes had higher frequency of cramps during dialysis, more often needed saline boluses and reduction in ultrafiltration [5].

However, a shortcoming of the RPV analysis used in the DRIP trial was the fact that slopes could only be analyzed retrospectively. Thus it remains to be demonstrated that applied methods for separating the slopes can be used routinely for dry weight prediction in real time, during the dialysis treatment. Such demonstrations would be essential for clinical practicability. Moreover, no absolute quantity of volume overload can currently be determined with the available RPV methods.

\section{Detection of Lung 'Water' Using Chest Ultrasound}

Upon performing chest ultrasound, 'lung comets' occur as hyperechoic artifacts in the presence of excessive lung 'water' [114]. A recently published study showed 
that patients with severe lung congestion measured by chest ultrasound were at much higher adjusted risk of death, compared with those who had mild or no congestion (HR 3.04, 95\% CI 1.73-5.35) [115]. A large multinational study is currently using lung comets to detect volume overload, and is testing the hypothesis that a treatment policy guided by systematic monitoring of lung 'water' as measured by chest ultrasound may reduce mortality, heart failure, and/or coronary heart disease events in HD patients [116]. Specifically, 250 patients in the intervention group, will receive intensification of ultrafiltration (longer and/or additional HD sessions), if $>15$ lung comets are detected. A sub-study will also compare BCM-based assessment of the fluid status with the chest ultrasound approach. Combining bioimpedance with chest ultrasound in a special patient population might be very interesting.

\section{Volume Overload in HD Patients: Review of Recent Reports}

\section{Prevalence of Volume Overload in HD Patients}

In a cross-sectional analysis of 2,125 patients who underwent BCM measurements in 34 European HD centers, $28.3 \%$ presented with predialysis volume overload $>15 \%$ ECV [8]. For a typical HD patient, 15\% ECV overload corresponds roughly to 2.5 liters of excess fluid. This threshold was previously shown to represent the highest quartile of a study population of HD patients [7]. At this threshold and above, complete fluid removal may not be reached during dialysis and normal fluid status will consequentially not likely be achieved, even immediately postdialysis.

\section{Volume Overload, Mortality and Clinical Outcomes in HD Patients}

In a blinded study, 208 prevalent HD patients were measured once with the BCM, and then followed over 78 months. Volume overload, defined once again by $>15 \%$ expansion of ECV predialysis (as in the previous studies $[8,12])$ was a significant predictor of all-cause mortality (HR 3.41, 95\% CI 1.62-7.17 [9].

Volume overload assessed by RPV monitoring was also associated with higher mortality [117]. Specifically, Agarwal [117] divided 308 prevalent patients into two groups about the median RPV slope and followed allcause mortality over 30 months. RPV slope measurements were of prognostic significance (HR 1.72 for flatter slopes, i.e. volume-overloaded patients (>1.39\%/h), 95\%
CI 1.14-2.58), while ultrafiltration volume, as a marker of IDWG, was not prognostically informative (HR 0.78 for higher ultrafiltration volume ( $>2.7$ liters), 95\% CI $0.51-$ 1.17). Although ultrafiltration volume and intradialytic weight loss are expected to correlate very strongly with IDWG [81], IDWG and ultrafiltration volume are not strictly the same, as the latter can be acutely reduced due to patient preference, hypotension, cramps, and/or modified by other factors.

Machek et al. [10] showed that BCM measurements can be used to guide a complete HD unit population towards normal volume status over the course of 1 year. In volume-overloaded patients, reduction to levels $<15 \%$ ECV also led to a reduction in blood pressure without an increase in intradialytic symptoms. Conversely, in volume-depleted patients, a slight increase in the fluid status led to a significant reduction in intradialytic symptoms.

\section{Association between Volume Overload and Interdialytic Weight Gain}

Patients in Agarwal's study who had flatter RPV slopes and were therefore likely to be volume overloaded [5] gained less weight between treatments [117]. In line with this finding, figure 2 demonstrates a significant inverse association between volume overload (postdialysis) and IDWG in a large number of patients treated in $60 \mathrm{HD}$ centers from 4 European countries (a similar analysis was previously presented [118], based on data shown at the ERA-EDTA 2010 [119]). Thus, HD patients who reach a state of volume depletion at the end of the HD treatment seem to subsequently gain greater amounts of weight, while the opposite seems to be true for those who are volume overloaded (methodological details in the figure legend).

Agarwal's findings [117] as well as our own data (although unadjusted) question the use of IDWG as an indicator of nonadherence. A rational approach to differentiate between IDWG as a predictable consequence of volume depletion versus IDWG due to voluntary fluid intake is thus to assess postdialysis volume status. In order to reduce IDWG after having ruled out volume depletion as the underlying cause, restriction of salt intake seems to be the most logical and effective approach [73], unless uncontrolled hyperglycemia in a diabetic patient influences IDWG.
Hecking et al. 


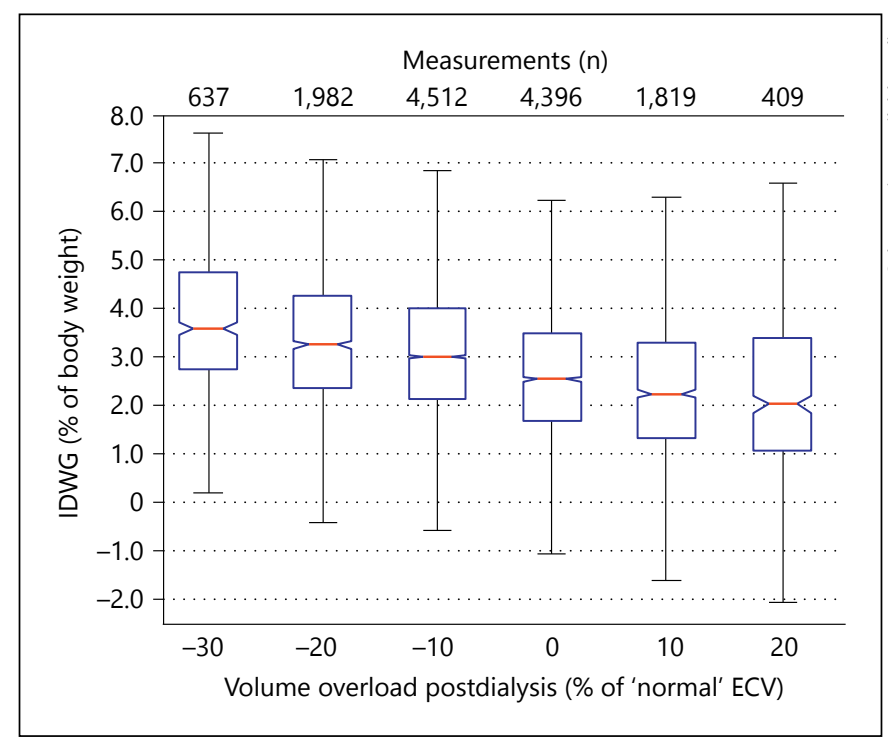

Fig. 2. Association between postdialysis volume status and IDWG. 14,942 measurements from 3,632 patients in 60 dialysis centers from 4 countries (NephroCare/Europe). BCM measurements were performed predialysis, as previously described [6], and yielded values for $\mathrm{VO}_{\text {pre }}$. IDWG was measured from BCM day to the next treatment. The majority (95.3\%) of all measurements were taken after a short interdialytic interval. $\mathrm{VO}_{\text {post }}$ was calculated as

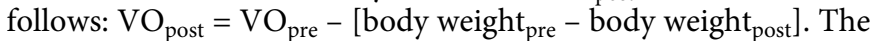
unadjusted association between $\mathrm{VO}_{\text {post }}$ and IDWG was determined using all measurements, but only $5-95 \%$ of the datapoints $\left(\mathrm{VO}_{\text {post }}\right.$ against IDWG) are displayed. Data in the figure show a significant, negative, unadjusted association between $\mathrm{VO}_{\text {post }}$ and subsequent IDWG $(\mathrm{R}=-0.20, \mathrm{p}<0.0001)$, indicating that $\mathrm{HD}$ patients who reach a state of volume depletion at the end of the HD treatment gain greater amounts of weight. Results were consistent when every patient was only included once $(R=-0.19, \mathrm{p}<$ 0.0001 ). Continuously expressed, IDWG was higher (by $0.32 \%$ of body weight), when $\mathrm{VO}_{\text {post }}$ was more negative (by $10 \% \mathrm{ECV}$ ). Description of the box: the central mark of each box is the median, the edges of the box are the 25th and 75th percentiles, and the whiskers extend to the most extreme of the displayed datapoints $(99.3 \%)$. VO = Volume overload; pre = predialysis; post $=$ postdialysis.

\section{Association between Predialysis Serum Sodium and Volume Overload}

It may be hypothesized that the strong inverse relationship between predialysis $\mathrm{SNa}$ and mortality is a consequence of volume overload being associated with both lower predialysis $\mathrm{SNa}$ and mortality [79]. This hypothesis was recently tested and reported [120], and the results are shown in figure $3 \mathrm{a}$ (methodological details in the figure legend). Interestingly, a significant, positive association was found between predialysis volume overload and predialy- sis $\mathrm{SNa}$, indicating that $\mathrm{HD}$ patients with greater amounts of volume overload do not have lower predialysis $\mathrm{SNa}$.

The reasons for this finding remain speculative. Higher SNa could be a readout for higher sodium intake. This hypothesis would agree with an acute increase in the $\mathrm{SNa}$ concentration observed under salt load in normotensive, healthy volunteers [121], however recent evidence suggests higher dietary salt intake may not be associated with higher SNa in HD patients [122]. Figure 3b demonstrates a negative association between predialysis $\mathrm{SNa}$ and IDWG, shown also in our analyses from the DOPPS [79, 81]. Thus the opposing associations with $\mathrm{SNa}$ in figure $3 \mathrm{a}$ and $b$ provide yet another indication that IDWG and volume overload are 'not one and the same'.

In summary, relatively rapid changes in volume status (IDWG), but not chronic volume overload, are associated with lower predialysis $\mathrm{SNa}$ concentration in $\mathrm{HD}$ patients. The significant but weak associations shown in figure 3 are unadjusted and should be verified in other datasets. More research about the relationship between $\mathrm{SNa}$, volume overload, IDWG, hypertension and perhaps intramuscular sodium content [123] might help to understand these puzzling relationships.

\section{Perspectives}

In the present article, we have emphasized that chronic volume overload and IDWG have different physiologic importance. Most importantly, volume overload is strikingly more strongly associated with mortality risk than IDWG, thus prevention of volume overload should be the primary goal. Severe postdialysis volume depletion also needs to be avoided since it may drive greater IDWG. Advising patients who consistently present with high IDWG to practice salt restriction (after having ruled out postdialysis volume depletion or uncontrolled hyperglycemia), and increasing dialysis treatment time, may enable the achievement of a close to normal volume status. As previously proposed [124], technical dry weight definitions should nowadays be added to clinical dry weight definitions [21].

An important word of caution must be applied: As striking as the mortality differences between volumeoverloaded versus higher IDWG patients may be, they are derived from observational data. Randomized controlled trials need to be designed to test the hypothesis that optimizing volume status improves clinical outcomes. If a randomized controlled, interventional trial on dry weight reduction in volume-overloaded HD patients was ade- 


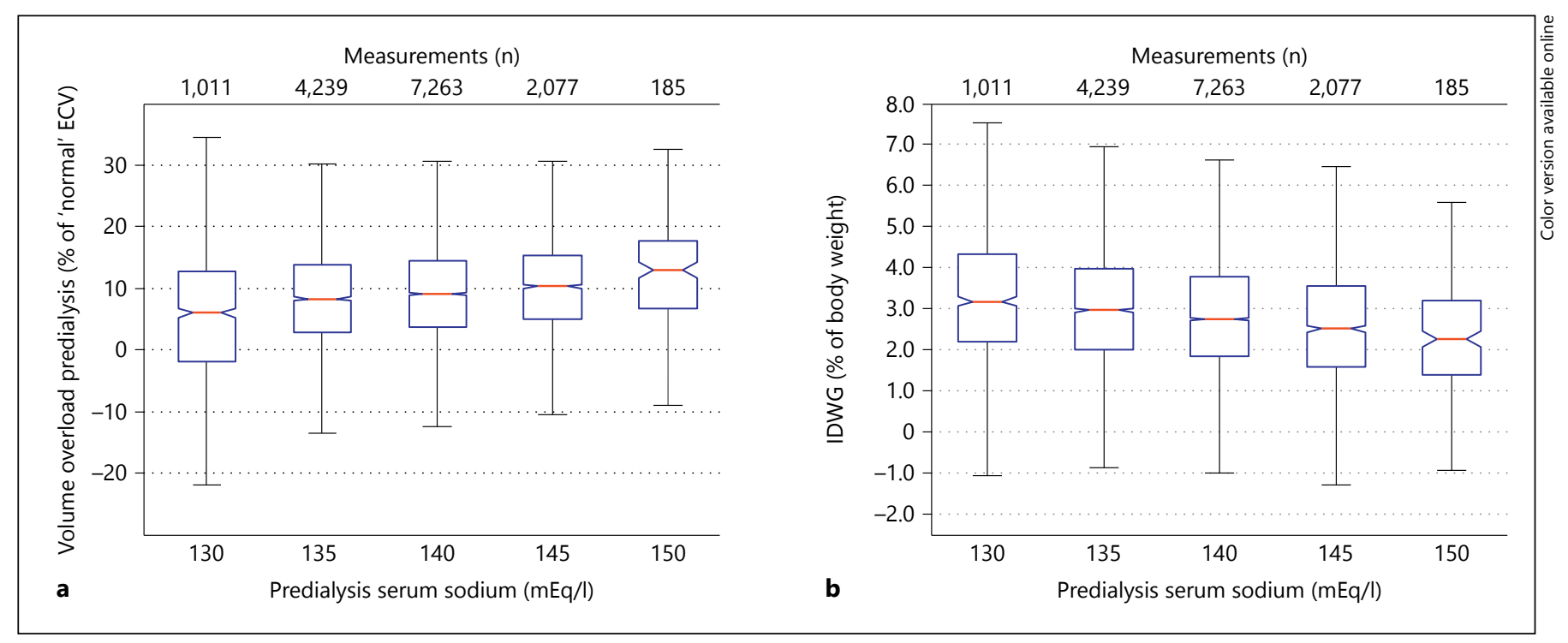

Fig. 3. Association between (a) predialysis volume status and (b) IDWG and the predialysis SNa concentration. 14,942 measurements from 3,632 patients in 60 dialysis centers from 4 countries (NephroCare/Europe). BCM measurements were performed predialysis, as previously described [6], and yielded values for $\mathrm{VO}_{\text {pre }}$. IDWG was measured from BCM day to the next treatment. The majority (95.3\%) of all measurements were taken after a short interdialytic interval. Unadjusted associations were calculated using all measurements, but only $5-95 \%$ of datapoints (predialysis $\mathrm{SNa}$ against $\mathrm{VO}_{\text {pre }}$, respectively IDWG) are displayed. a Significant, positive, unadjusted association between $\mathrm{VO}_{\text {pre }}$ and predialysis $\mathrm{SNa}(\mathrm{R}=0.12, \mathrm{p}<0.0001)$, indicating that HD patients who are volume overloaded have higher predialysis $\mathrm{SNa}$ concentrations. Results were consistent when every patient was only included once $(\mathrm{R}=0.12, \mathrm{p}<0.0001)$. Continuously expressed, $\mathrm{VO}_{\text {pre }}$ was higher, by $2.9 \% \mathrm{ECV}$, for every $10 \mathrm{mEq} / \mathrm{l}$ higher the predialysis $\mathrm{SNa}$ concentration. Whilst statistically significant, the association was very weak. Of note, $\mathrm{VO}_{\text {pre }}$ was measured by BCM within 14 days of the

quately powered for hard endpoints, several technical aspects might become important determinants of its success. Among them, the measurement to determine dry weight and the method of dry weight reduction might be the most crucial.

Recently completed, controlled studies have been testing prospectively if regulated ultrafiltration may assist rapid removal of volume overload [125] and whether an improved volume status improves the cardiac condition [126]. The results of these studies will prove useful for a trial aimed at improving outcomes in HD patients. Until such a project is finally realized however, we, again, feel obliged to recommend reaching out for objective measures of volume status, thereby surpassing mere evaluations of IDWG. predialysis SNa measurement; it is likely that the association would have been stronger if predialysis $\mathrm{SNa}$ and $\mathrm{VO}_{\text {pre }}$ had been measured on the same day. $\mathbf{b}$ Significant, negative, unadjusted association between IDWG and predialysis SNa $(\mathrm{R}=-0.09, \mathrm{p}<0.0001)$, indicating that HD patients with higher IDWG tend to have lower predialysis $\mathrm{SNa}$ concentrations. Results were consistent when every patient was only included once $(\mathrm{R}=-0.09, \mathrm{p}<0.0001)$. Continuously expressed, IDWG was higher, by $0.5 \%$ of body weight, for every $10 \mathrm{mEq} / \mathrm{l}$ lower the predialysis SNa concentration. Whilst statistically significant, the association was very weak, although confirmatory of previous results $[79,81]$. Of note, IDWG was determined within 14 days of the predialysis SNa measurement; it is likely that the association would have been stronger if predialysis $\mathrm{SNa}$ and IDWG had been measured on the same day. Description of the box: the central mark of each box is the median, the edges of the box are the 25th and 75th percentiles, and the whiskers extend to the most extreme of the displayed datapoints (99.3\%). VO = Volume overload; pre $=$ predialysis.

\section{Acknowledgement}

We thank Heather Van Doren, employee of Arbor Research Collaborative for Health, for editorial assistance.

\section{Disclosure Statement}

C. Chazot and W.H. Hörl previously received speaker honoraria and/or research grants from Fresenius Medical Care. P. Kotanko, N. Levin, P. Wabel and U. Moissl currently hold stock in Fresenius Medical Care. P. Wabel and U. Moissl are employees of Fresenius Medical Care in Germany, which produces the BCMBody Composition Monitor. N. Levin is holding the following patents in the United States in the field of bioimpedance spectroscopy: 'Bioimpedance methods and apparatus' (application No. 13/107246, patent reference 040034US05, patent No. 8257280); 'Bioimpedance 
methods and apparatus' (application No. 10/570368, patent reference 040034US04, patent No. 7945317); 'Device and method for the determination of dry weight by continuous measurement of resistance and calculation of circumference in a body segment using segmental bioimpedance analysis' (application No. 11/246635, patent reference 000003US04, patent No. 7801598). P. Wabel is holding the following patents in the United States in the field of bioimpedance spectroscopy: 'Method and a device for determining the hydration and/or nutrition status of a patient' (application No. 11/630967, patent reference 035018US01, patent No. 7917202); 'Method and a device for determining the hydration and/or nutrition status of a patient' (application No. 11/630965, patent reference 045010 US02, patent No. 8340754). None of the authors have further conflicts of interest to disclose.

\section{References}

$\checkmark 1$ Chazot C, Collonge C, Charra B: Low sodium diet for dialysis patients: myth or reality? (in French) Nephrol Ther 2007;3(suppl 2):S137S140.

$\checkmark 2$ Tzamaloukas AH, Levinstone AR, Gardner KD Jr: Hyperglycemia in advanced renal failure: sodium and water metabolism. Nephron 1982;31:40-44.

-3 Bots CP, Brand HS, Veerman EC, ValentijnBenz M, Van Amerongen BM, Valentijn RM, Vos PF, Bijlsma JA, Bezemer PD, Ter Wee $\mathrm{PM}$, Amerongen AV: Interdialytic weight gain in patients on hemodialysis is associated with dry mouth and thirst. Kidney Int 2004; 66:1662-1668.

$\checkmark 4$ Liu L, Zhu F, Raimann J, Thijssen S, Sipahioglu MH, Wystrychowski G, Kitzler T, Tetta C, Wabel P, Kotanko P, Levin NW: Determination of fluid status in haemodialysis patients with whole-body and calf bioimpedance techniques. Nephrology (Carlton) 2012;17:131140.

5 Sinha AD, Light RP, Agarwal R: Relative plasma volume monitoring during hemodialysis aids the assessment of dry weight. Hypertension 2010;55:305-311.

6 Wabel P, Chamney P, Moissl U, Jirka T: Importance of whole-body bioimpedance spectroscopy for the management of fluid balance. Blood Purif 2009;27:75-80.

7 Wabel P, Moissl U, Chamney P, Jirka T, Machek P, Ponce P, Taborsky P, Tetta C, Velasco N, Vlasak J, Zaluska W, Wizemann V: Towards improved cardiovascular management: the necessity of combining blood pressure and fluid overload. Nephrol Dial Transplant 2008;23:2965-2971.

-8 Passauer J, Petrov H, Schleser A, Leicht J, Pucalka K: Evaluation of clinical dry weight assessment in haemodialysis patients using bioimpedance spectroscopy: a cross-sectional study. Nephrol Dial Transplant 2010;25:545551.

$\checkmark 9$ Chazot C, Wabel P, Chamney P, Moissl U, Wieskotten S, Wizemann V: Importance of normohydration for the long-term survival of haemodialysis patients. Nephrol Dial Transplant 2012;27:2404-2410.

10 Machek P, Jirka T, Moissl U, Chamney P, Wabel P: Guided optimization of fluid status in haemodialysis patients. Nephrol Dial Transplant 2010;25:538-544.

11 Van Biesen W, Williams JD, Covic AC, Fan S, Claes K, Lichodziejewska-Niemierko M,
Verger C, Steiger J, Schoder V, Wabel P, Gauly A, Himmele R: Fluid status in peritoneal dialysis patients: the European Body Composition Monitoring (EuroBCM) study cohort. PLoS One 2011;6:e17148.

12 Wizemann V, Wabel P, Chamney P, Zaluska W, Moissl U, Rode C, Malecka-Masalska T, Marcelli D: The mortality risk of overhydration in haemodialysis patients. Nephrol Dial Transplant 2009;24:1574-1579.

13 Scribner BH, Buri R, Caner JE, Hegstrom R, Burnell JM: The treatment of chronic uremia by means of intermittent hemodialysis: a preliminary report. Trans Am Soc Artif Intern Organs 1960;6:114-122.

14 Guyton AC: Physiologic regulation of arterial pressure. Am J Cardiol 1961;8:401-407.

15 Guyton AC: Circulatory Physiology. III. Arterial Pressure and Hypertension. Philadelphia, Saunders, 1980.

16 Braam B, Jindal K, Dorhout M, Evert J: Hypertension and Cardiovascular Aspects of Dialysis Treatment: Clinical Management of Volume Control. Lengerich, Pabst Science, 2011.

17 Kasner M, Westermann D, Steendijk P, Gaub R, Wilkenshoff U, Weitmann K, Hoffmann W, Poller W, Schultheiss HP, Pauschinger M, Tschope C: Utility of Doppler echocardiography and tissue Doppler imaging in the estimation of diastolic function in heart failure with normal ejection fraction: a comparative Doppler-conductance catheterization study. Circulation 2007;116:637-647.

18 Charra B, Chazot C: Volume control, blood pressure and cardiovascular function. Lessons from hemodialysis treatment. Nephron Physiol 2003;93:94-101.

19 Levin NW, Zhu F, Keen M: Interdialytic weight gain and dry weight. Blood Purif 2001; 19:217-221.

20 Agarwal R, Weir MR: Dry weight: a concept revisited in an effort to avoid medication-directed approaches for blood pressure control in hemodialysis patients. Clin J Am Soc Nephrol 2010;5:1255-1260.

21 Charra B, Laurent G, Chazot C, Calemard E, Terrat JC, Vanel T, Jean G, Ruffet M: Clinical assessment of dry weight. Nephrol Dial Transplant 1996;11(suppl 2):16-19.

22 Kayikcioglu M, Tumuklu M, Ozkahya M, Ozdogan O, Asci G, Duman S, Toz H, Can LH, Basci A, Ok E: The benefit of salt restriction in the treatment of end-stage renal dis- ease by haemodialysis. Nephrol Dial Transplant 2009;24:956-962.

23 Charra B, Chazot C, Jean G, Laurent G: Long, slow dialysis. Miner Electrolyte Metab 1999; 25:391-396.

24 Ozkahya M, Ok E, Toz H, Asci G, Duman S, Basci A, Kose T, Dorhout Mees EJ: Long-term survival rates in haemodialysis patients treated with strict volume control. Nephrol Dial Transplant 2006;21:3506-3513.

25 Robinson BM, Tong L, Zhang J, Wolfe RA, Goodkin DA, Greenwood RN, Kerr PG, Morgenstern H, Li Y, Pisoni RL, Saran R, Tentori F, Akizawa T, Fukuhara S, Port FK: Blood pressure levels and mortality risk among hemodialysis patients in the dialysis outcomes and practice patterns study. Kidney Int 2012;82:570-580.

26 Dionisio P, Valenti M, Bergia R, Caramello E, Stramignoni E, Berto IM, Pellerey M, Bajardi $P$ : Influence of the hydration state on blood pressure values in a group of patients on regular maintenance hemodialysis. Blood Purif 1997; 15:25-33.

27 Chazot C, Vo-Van C, Deleaval P, Lorriaux C, Hurot JM, Mayor B, Jean G: Predialysis systolic blood pressure evolution in incident hemodialysis patients: effects of the dry weight method and prognostic value. Blood Purif 2012;33:275-283.

28 Morduchowicz G, Sulkes J, Aizic S, Gabbay U, Winkler J, Boner G: Compliance in hemodialysis patients: a multivariate regression analysis. Nephron 1993;64:365-368.

29 Kimmel PL, Peterson RA, Weihs KL, Simmens SJ, Boyle DH, Verme D, Umana WO, Veis JH, Alleyne S, Cruz I: Behavioral compliance with dialysis prescription in hemodialysis patients. J Am Soc Nephrol 1995;5:1826-1834.

30 Safdar N, Baakza H, Kumar H, Naqvi SA: Non-compliance to diet and fluid restrictions in haemodialysis patients. J Pak Med Assoc 1995;45:293-295.

31 Casey J, Johnson V, McClelland P: The relationship between interdialytic weight gain and patient compliance. A single-centred cohort study $(\mathrm{n}=21)$. EDTNA ERCA J 2001;27: 187-189.

32 Takaki J, Nishi T, Shimoyama H, Inada T, Matsuyama N, Sasaki T, Kumano H, Kuboki T: Possible variances of blood urea nitrogen, serum potassium and phosphorus levels and interdialytic weight gain accounted for compliance of hemodialysis patients. J Psychosom Res 2003;55:525-529. 
33 Hecking E, Bragg-Gresham JL, Rayner HC, Pisoni RL, Andreucci VE, Combe C, Greenwood R, McCullough K, Feldman HI, Young EW, Held PJ, Port FK: Haemodialysis prescription, adherence and nutritional indicators in five European countries: results from the Dialysis Outcomes and Practice Patterns Study (DOPPS). Nephrol Dial Transplant 2004;19:100-107.

-34 Takaki J, Yano E: Possible gender differences in the relationships of self-efficacy and the internal locus of control with compliance in hemodialysis patients. Behav Med 2006;32:5-11.

- 35 Barnett T, Li Yoong T, Pinikahana J, Si-Yen T: Fluid compliance among patients having haemodialysis: can an educational programme make a difference? J Adv Nurs 2008; 61:300-306.

-36 Lindberg M, Prutz KG, Lindberg P, Wikstrom $\mathrm{B}$ : Interdialytic weight gain and ultrafiltration rate in hemodialysis: lessons about fluid adherence from a national registry of clinical practice. Hemodial Int 2009;13:181-188.

- 37 Rambod M, Peyravi H, Shokrpour N, Sareban MT: Dietary and fluid adherence in Iranian hemodialysis patients. Health Care Manag (Frederick) 2010;29:359-364.

- 38 Saran R, Bragg-Gresham JL, Rayner HC, Goodkin DA, Keen ML, Van Dijk PC, Kurokawa K, Piera L, Saito A, Fukuhara S, Young EW, Held PJ, Port FK: Nonadherence in hemodialysis: associations with mortality, hospitalization, and practice patterns in the DOPPS. Kidney Int 2003;64:254-262.

-39 Hegel MT, Ayllon T, Thiel G, Oulton B: Improving adherence to fluid restrictions in male hemodialysis patients: a comparison of cognitive and behavioral approaches. Health Psychol 1992;11:324-330.

$\checkmark 40$ Berg J, York S, Cormier S, Warsaba D: Patient education. Incentive program to control interdialytic weight gains. J Ren Nutr 2004;14: 52-59.

41 Jacob S, Locking-Cusolito H: Thirst distress and interdialytic weight gain: how do they relate? CANNT J 2004;14:33-37.

42 Sharp J, Wild MR, Gumley AI, Deighan CJ: A cognitive behavioral group approach to enhance adherence to hemodialysis fluid restrictions: a randomized controlled trial. Am J Kidney Dis 2005;45:1046-1057.

43 Sun JH, Lin CC: Using self-regulation theory to develop an intervention protocol for fluid control in patients undergoing hemodialysis (in Chinese). Hu Li Za Zhi 2006;53:80-85.

$\checkmark 44$ Ghaddar S, Shamseddeen W, Elzein H: Behavioral modeling to guide adherence to fluid control in hemodialysis patients. J Ren Nutr 2009; 19:153-160.

45 O'Connor SM, Jardine AG, Millar K: The prediction of self-care behaviors in end-stage renal disease patients using Leventhal's self-regulatory model. J Psychosom Res 2008;65:191-200.

46 Sinclair PM, Parker V: Pictures and perspectives: a unique reflection on interdialytic weight gain. Nephrol Nurs J 2009;36:589596; quiz 597.
47 Chilcot J, Wellsted D, Farrington K: Illness representations are associated with fluid nonadherence among hemodialysis patients. J Psychosom Res 2010;68:203-212.

48 Everett KD, Brantley PJ, Sletten C, Jones GN, McKnight GT: The relation of stress and depression to interdialytic weight gain in hemodialysis patients. Behav Med 1995;21:25-30.

49 Taskapan H, Ates F, Kaya B, Emul M, Kaya M, Taskapan C, Sahin I: Psychiatric disorders and large interdialytic weight gain in patients on chronic haemodialysis. Nephrology (Carlton) $2005 ; 10: 15-20$.

50 Sharp J, Wild MR, Gumley AI: A systematic review of psychological interventions for the treatment of nonadherence to fluid-intake restrictions in people receiving hemodialysis. Am J Kidney Dis 2005;45:15-27.

51 Ifudu O, Dulin AL, Friedman EA: Interdialytic weight gain correlates with glycosylated hemoglobin in diabetic hemodialysis patients. Am J Kidney Dis 1994;23:686-691.

52 Sherman RA, Cody RP, Rogers ME, Solanchick JC: Interdialytic weight gain and nutritional parameters in chronic hemodialysis patients. Am J Kidney Dis 1995;25:579-583.

53 Testa A, Beaud JM: The other side of the coin: Interdialytic weight gain as an index of good nutrition. Am J Kidney Dis 1998;31:830-834.

54 Testa A, Plou A: Clinical determinants of interdialytic weight gain. J Ren Nutr 2001;11: 155-160.

55 Sezer S, Ozdemir FN, Arat Z, Perim O, Turan M, Haberal M: The association of interdialytic weight gain with nutritional parameters and mortality risk in hemodialysis patients. Ren Fail 2002;24:37-48.

-56 Ifudu O, Uribarri J, Rajwani I, Vlacich V, Reydel K, Delosreyes G, Friedman EA: Relation between interdialytic weight gain, body weight and nutrition in hemodialysis patients. Am J Nephrol 2002;22:363-368.

57 Lopez-Gomez JM, Villaverde M, Jofre R, Rodriguez-Benitez P, Perez-Garcia R: Interdialytic weight gain as a marker of blood pressure, nutrition, and survival in hemodialysis patients. Kidney Int Suppl 2005;S 93:S63-S68.

58 Maduell F, Navarro V: Assessment of salt intake in hemodialysis (in Spanish). Nefrologia 2001;21:71-77.

-59 Ozkahya M, Toz H, Unsal A, Ozerkan F, Asci G, Gurgun C, Akcicek F, Mees EJ: Treatment of hypertension in dialysis patients by ultrafiltration: role of cardiac dilatation and time factor. Am J Kidney Dis 1999;34:218-221.

60 Krautzig S, Janssen U, Koch KM, Granolleras $\mathrm{C}$, Shaldon S: Dietary salt restriction and reduction of dialysate sodium to control hypertension in maintenance haemodialysis patients. Nephrol Dial Transplant 1998;13:552-553.

61 Lindley EJ: Reducing sodium intake in hemodialysis patients. Semin Dial 2009;22:260263.

62 Manlucu J, Gallo K, Heidenheim PA, Lindsay RM: Lowering postdialysis plasma sodium (conductivity) to increase sodium removal in volume-expanded hemodialysis patients: a pilot study using a biofeedback software system. Am J Kidney Dis 2010;56:69-76.

63 Penne EL, Sergeyeva O: Sodium gradient: a tool to individualize dialysate sodium prescription in chronic hemodialysis patients? Blood Purif 2011;31:86-91.

64 Flanigan MJ: How should dialysis fluid be individualized for the chronic hemodialysis patient? Sodium. Semin Dial 2008;21:226-229.

65 Munoz Mendoza J, Sun S, Chertow GM, Moran J, Doss S, Schiller B: Dialysate sodium and sodium gradient in maintenance hemodialysis: a neglected sodium restriction approach? Nephrol Dial Transplant 2011;26:1281-1287.

66 Lomonte C, Basile C: Do not forget to individualize dialysate sodium prescription. Nephrol Dial Transplant 2011;26:1126-1128.

67 Santos SF, Peixoto AJ: Revisiting the dialysate sodium prescription as a tool for better blood pressure and interdialytic weight gain management in hemodialysis patients. Clin J Am Soc Nephrol 2008;3:522-530.

68 Davenport A, Cox C, Thuraisingham R, PanThames Renal Audit G: The importance of dialysate sodium concentration in determining interdialytic weight gains in chronic hemodialysis patients: the PanThames Renal Audit. Int J Artif Organs 2008;31:411-417.

69 Hecking M, Kainz A, Horl WH, Herkner H, Sunder-Plassmann G: Sodium setpoint and sodium gradient: influence on plasma sodium change and weight gain. Am J Nephrol 2011; 33:39-48.

70 Keen ML, Gotch FA: The association of the sodium 'setpoint' to interdialytic weight gain and blood pressure in hemodialysis patients. Int J Artif Organs 2007;30:971-979.

71 Santos SF, Peixoto AJ: Sodium balance in maintenance hemodialysis. Semin Dial 2010; 23:549-555.

72 Davenport A: Interdialytic weight gain in diabetic haemodialysis patients and diabetic control as assessed by glycated haemoglobin. Nephron Clin Pract 2009;113:c33-c37.

73 Tomson CR: Advising dialysis patients to restrict fluid intake without restricting sodium intake is not based on evidence and is a waste of time. Nephrol Dial Transplant 2001;16: 1538-1542.

74 Dorhout Mees EJ: Thirst in dialysis patients. Kidney Int 2005;67:1192; author reply 11921193.

75 Foley RN, Herzog CA, Collins AJ; United States Renal Data S: Blood pressure and longterm mortality in United States hemodialysis patients: USRDS waves 3 and 4 study. Kidney Int 2002;62:1784-1790.

76 Kalantar-Zadeh K, Regidor DL, Kovesdy CP, Van Wyck D, Bunnapradist S, Horwich TB, Fonarow GC: Fluid retention is associated with cardiovascular mortality in patients undergoing long-term hemodialysis. Circulation 2009;119:671-679.

77 Flythe JE, Kimmel SE, Brunelli SM: Rapid fluid removal during dialysis is associated with cardiovascular morbidity and mortality. Kidney Int 2011;79:250-257. 
78 Saran R, Bragg-Gresham JL, Levin NW, Twardowski ZJ, Wizemann V, Saito A, Kimata N, Gillespie BW, Combe C, Bommer J, Akiba T, Mapes DL, Young EW, Port FK: Longer treatment time and slower ultrafiltration in hemodialysis: associations with reduced mortality in the DOPPS. Kidney Int 2006;69: $1222-1228$

79 Hecking M, Karaboyas A, Saran R, Sen A, Horl WH, Pisoni RL, Robinson BM, SunderPlassmann G, Port FK: Predialysis serum sodium level, dialysate sodium, and mortality in maintenance hemodialysis patients: the Dialysis Outcomes and Practice Patterns Study (DOPPS). Am J Kidney Dis 2012;59: 238-248.

80 Waikar SS, Curhan GC, Brunelli SM: Mortality associated with low serum sodium concentration in maintenance hemodialysis. Am J Med 2011;124:77-84.

81 Hecking M, Karaboyas A, Saran R, Sen A, Inaba M, Rayner H, Horl WH, Pisoni RL, Robinson BM, Sunder-Plassmann G, Port FK: Dialysate sodium concentration and the association with interdialytic weight gain, hospitalization, and mortality. Clin J Am Soc Nephrol 2012;7: 92-100.

82 De Paula FM, Peixoto AJ, Pinto LV, Dorigo D, Patricio PJ, Santos SF: Clinical consequences of an individualized dialysate sodium prescription in hemodialysis patients. Kidney Int 2004;66:1232-1238.

83 Hecking M, Karaboyas A, Port FK: Dialysate sodium and mortality. Letter to the editor, submitted to NDT Full text available online (NDT website) as E-letter 2012.

84 Chazot C: Managing dry weight and hypertension in dialysis patients: still a challenge for the nephrologist in 2009? J Nephrol 2009;22: 587-597.

85 Franz M, Pohanka E, Tribl B, Woloszczuk W, Horl WH: Living on chronic hemodialysis between dryness and fluid overload. Kidney Int Suppl 1997;59:S39-S42.

\$86 Kraemer M, Rode C, Wizemann V: Detection limit of methods to assess fluid status changes in dialysis patients. Kidney Int 2006;69:16091620.

-87 Talartschik J, Eisenhauer T, Voth E, Sold G, Scheler F: Is the plasma ANP level an index of volume expansion in dialysis patients? (in German) Z Kardiol 1988;77(suppl 2):72-77.

88 De Chatel R, Mako J, Toth M, Barna I, Lang RE: Atrial natriuretic peptide in patients with chronic renal failure on maintenance haemodialysis. Int Urol Nephrol 1991;23:177183.

89 Lee SW, Song JH, Kim GA, Lim HJ, Kim MJ: Plasma brain natriuretic peptide concentration on assessment of hydration status in hemodialysis patient. Am J Kidney Dis 2003;41: $1257-1266$

-90 Ishibe S, Peixoto AJ: Methods of assessment of volume status and intercompartmental fluid shifts in hemodialysis patients: implications in clinical practice. Semin Dial 2004;17: $37-43$.
\$1 Chazot C, Vo-Van C, Zaoui E, Vanel T, Hurot JM, Lorriaux C, Mayor B, Deleaval P, Jean G: Fluid overload correction and cardiac history influence brain natriuretic peptide evolution in incident haemodialysis patients. Nephrol Dial Transplant 2011;26: 2630-2634.

92 Metagenics, USA, 2009: Frequently asked questions about bioimpedance analysis and imp df50 device.

93 University College London: Brief introduction to bioimpedance. http://www.Ucl.Ac. Uk/medphys/research/eit/pubs/bioimpedance_overview.pdf.

94 Dou Y, Zhu F, Kotanko P: Assessment of extracellular fluid volume and fluid status in hemodialysis patients: current status and technical advances. Semin Dial 2012;25: 377-387.

95 Zhu F, Kuhlmann MK, Kotanko P, Seibert E, Leonard EF, Levin NW: A method for the estimation of hydration state during hemodialysis using a calf bioimpedance technique. Physiol Meas 2008;29:S503-S516.

-96 Zhu F, Kotanko P, Handelman GJ, Raimann JG, Liu L, Carter M, Kuhlmann MK, Seibert E, Leonard EF, Levin NW: Estimation of normal hydration in dialysis patients using whole body and calf bioimpedance analysis. Physiol Meas 2011;32:887-902.

$\checkmark 97$ Zhu F, Leonard EF, Carter M, Levin NW: Continuous measurement of calf resistivity in hemodialysis patients using bioimpedance analysis. Conf Proc IEEE Eng Med Biol Soc 2006;1:5126-5128.

98 Chamney PW, Wabel P, Moissl UM, Muller MJ, Bosy-Westphal A, Korth O, Fuller NJ: A whole-body model to distinguish excess fluid from the hydration of major body tissues. Am J Clin Nutr 2007;85:80-89.

$\$ 99$ Wang J, Pierson RN Jr: Disparate hydration of adipose and lean tissue require a new model for body water distribution in man. J Nutr 1976;106:1687-1693.

100 Steuer RR, Harris DH, Weiss RL, Biddulph $\mathrm{MC}$, Conis JM: Evaluation of a noninvasive hematocrit monitor: a new technology. Am Clin Lab 1991;10:20-22.

101 Mancini E, Santoro A, Spongano M, Paolini F, Rossi M, Zucchelli P: Continuous on-line optical absorbance recording of blood volume changes during hemodialysis. Artif Organs 1993;17:691-694.

102 Paolini F, Mancini E, Bosetto A, Santoro A: Hemoscan: a dialysis machine-integrated blood volume monitor. Int J Artif Organs 1995;18:487-494.

103 Steuer RHD, Conis J: A new optical technique for monitoring hematocrit and circulating blood volume: its application in renal dialysis. Dial Transplant 1993;22:260-265.

104 Dasselaar JJ, Huisman RM, de Jong PE, Franssen CF: Measurement of relative blood volume changes during haemodialysis: merits and limitations. Nephrol Dial Transplant 2005;20:2043-2049.
105 Johner C, Chamney PW, Schneditz D, Kramer M: Evaluation of an ultrasonic blood volume monitor. Nephrol Dial Transplant 1998; 13:2098-2103.

106 Schneditz D, Pogglitsch H, Horina J, Binswanger U: A blood protein monitor for the continuous measurement of blood volume changes during hemodialysis. Kidney Int 1990;38:342-346.

107 Steuer RR, Leypoldt JK, Cheung AK, Harris $\mathrm{DH}$, Conis JM: Hematocrit as an indicator of blood volume and a predictor of intradialytic morbid events. ASAIO J 1994;40:M691M696.

108 Steuer RR, Leypoldt JK, Cheung AK, Senekjian HO, Conis JM: Reducing symptoms during hemodialysis by continuously monitoring the hematocrit. Am J Kidney Dis 1996;27: 525-532.

109 Andrulli S, Colzani S, Mascia F, Lucchi L, Stipo L, Bigi MC, Crepaldi M, Redaelli B, Albertazzi A, Locatelli F: The role of blood volume reduction in the genesis of intradialytic hypotension. Am J Kidney Dis 2002;40: 1244-1254.

110 Barth C, Boer W, Garzoni D, Kuenzi T, Ries W, Schaefer R, Schneditz D, Tsobanelis T, van der Sande F, Wojke R, Schilling H, PasslickDeetjen J: Characteristics of hypotensionprone haemodialysis patients: is there a critical relative blood volume? Nephrol Dial Transplant 2003;18:1353-1360.

111 Reddan DN, Szczech LA, Hasselblad V, Lowrie EG, Lindsay RM, Himmelfarb J, Toto RD, Stivelman J, Winchester JF, Zillman LA, Califf RM, Owen WF Jr: Intradialytic blood volume monitoring in ambulatory hemodialysis patients: a randomized trial. J Am Soc Nephrol 2005;16:2162-2169.

112 Lopot F, Kotyk P, Blaha J, Forejt J: Use of continuous blood volume monitoring to detect inadequately high dry weight. Int J Artif Organs 1996;19:411-414.

113 Agarwal R, Alborzi P, Satyan S, Light RP: Dry Weight Reduction in Hypertensive Hemodialysis Patients (DRIP): a randomized, controlled trial. Hypertension 2009;53:500507.

114 Picano E, Frassi F, Agricola E, Gligorova S, Gargani L, Mottola G: Ultrasound lung comets: a clinically useful sign of extravascular lung water. J Am Soc Echocardiogr 2006; 19:356-363.

115 Zoccali C, Torino C, Tripepi R, Tripepi G, D’Arrigo G, Postorino M, Gargani L, Sicari R, Picano E, Mallamaci F: Pulmonary congestion predicts cardiac events and mortality in ESRD. J Am Soc Nephrol 2013;24:639646.

116 Zoccali C, Ortiz A, Massy Z, Covic A, Fliser D, Suleymanlar G, Martinez-Castelao A, London GM, Goldsmith D, Wiecek A: Lung water by ultrasound-guided treatment to prevent death and cardiovascular complications in high risk end-stage renal disease patients with cardiomyopathy (LUST) - grant application. ERA-EDTA, 2011. 
117 Agarwal R: Hypervolemia is associated with increased mortality among hemodialysis patients. Hypertension 2010;56:512-517.

118 Wizemann V: Body composition - how to determine dry weight. Heidelberg, Dialysis Academy, 2010.

119 Wabel P, Jirka T, Wizemann V, Zaluska W, Ponce P, Moissl U, Wieskotten S, Chamney P: Prevalence of fluid overload in European HD patients. ERA-EDTA Poster; NDT Plus 2010;3(suppl 3):iii191-iii192.

120 Hecking M, Karaboyas A, Antlanger M, Saran R, Wizemann V, Chazot C, Rayner H, Hörl WH, Pisoni R, Robinson B, SunderPlassmann G, Moissl U, Kotanko P, Levin NW, Saemann MD, Kalantar-Zadeh K, Port FK, Wabel P: Interdialytic weight gain versus chronic fluid overload: relationships with serum sodium and mortality. Austrian Society of Nephrology Annual Conference, Graz, September 2012.
121 Suckling RJ, He FJ, Markandu ND, MacGregor GA: Dietary salt influences postprandial plasma sodium concentration and systolic blood pressure. Kidney Int 2012;81: 407-411.

122 McCausland FR, Waikar SS, Brunelli SM Increased dietary sodium is independently associated with greater mortality among prevalent hemodialysis patients. Kidney Int 2012;82:204-211.

123 Kopp C, Linz P, Wachsmuth L, Dahlmann A, Horbach T, Schofl C, Renz W, Santoro D, Niendorf T, Muller DN, Neininger M, Cavallaro A, Eckardt KU, Schmieder RE, Luft FC, Uder M, Titze J: ${ }^{23} \mathrm{Na}$ magnetic resonance imaging of tissue sodium. Hypertension 2012;59:167-172.
24 Sinha AD, Agarwal R: Can chronic volume overload be recognized and prevented in hemodialysis patients? The pitfalls of the clinical examination in assessing volume status. Semin Dial 2009;22:480-482.

125 Hecking M, Antlanger M, Winnicki W, Reiter T, Werzowa J, Haidinger M, Weichhart T, Polaschegg HD, Josten P, Exner I, Lorenz-Turnheim K, Eigner M, Paul G, Klauser-Braun R, Horl WH, Sunder-Plassmann G, Saemann MD: Blood volumemonitored regulation of ultrafiltration in fluid-overloaded hemodialysis patients: study protocol for a randomized controlled trial. Trials 2012;13:79.

126 Ok E: Effects of volume control guided by body composition monitor (BCM) on blood pressure and cardiac condition in hemodialysis patients. ClinicalTrials. Gov. Study Protocol No. NCT00974857, 2009. 